\title{
Public Participation and Governance Performance in Gender-Imbalanced Central Rural China: The Roles of Trust and Risk Perception
}

\author{
Ruixia Song ${ }^{1, *} \mathbb{C}$, Shuzhuo $\mathrm{Li}^{1}$ and Marcus W. Feldman ${ }^{2} \mathbb{D}$ \\ 1 Institute for Population and Development Studies, School of Public Policy and Administration, Xi'an Jiaotong \\ University, Xi'an 710049, China; shzhli@xjtu.edu.cn \\ 2 Morrison Institute for Population and Resource Studies, Department of Biology, Stanford University, Stanford, \\ CA 94305, USA; mfeldman@stanford.edu \\ * Correspondence: song121854@stu.xjtu.edu.cn
}

Citation: Song, Ruixia, Shuzhuo Li, and Marcus W. Feldman. 2021. Public Participation and Governance

Performance in Gender-Imbalanced Central Rural China: The Roles of Trust and Risk Perception. Social Sciences 10: 243. https://doi.org/ $10.3390 /$ socsci10070243

Academic Editor: Nigel Parton

Received: 18 May 2021

Accepted: 22 June 2021

Published: 25 June 2021

Publisher's Note: MDPI stays neutral with regard to jurisdictional claims in published maps and institutional affiliations.

Copyright: (c) 2021 by the authors. Licensee MDPI, Basel, Switzerland. This article is an open access article distributed under the terms and conditions of the Creative Commons Attribution (CC BY) license (https:// creativecommons.org/licenses/by/ $4.0 /)$.

\begin{abstract}
The study investigates the impact of public participation on governance performance in a risk society. A trust-based participatory paradigm is proposed as a viable framework. Using data from a 2018 survey of family planning services in Hubei, China, this study develops hypotheses drawn from causal mechanisms of participatory governance. A structural equation modeling (SEM) approach is employed to disentangle the direct effect of public participation on governance performance from its indirect effect through trust. Moderated multiple regressions (MMR) are conducted to identify the moderating effect of risk perception. The results indicate that public participation is associated with higher perceived quality of family planning services and decreases son preference through the serial mediation effects of trust and perceived quality. Risk perception of gender imbalance magnifies the positive effect of civic autonomy on perceived quality. This paper extends previous research on the governance of gender imbalance and contributes to the literature on the relationship between public participation, trust, risk perception, and governance performance in authoritarian countries.
\end{abstract}

Keywords: public participation; governance performance; trust; risk perception; gender imbalance; family planning services; China

\section{Introduction}

Since the 1980s, the sex ratio at birth (SRB) in China has risen from 111.3 in 1990 to 119.9 in 2000 and reached 120.5 in 2005. Although the SRB declined to 118.1 in 2010 and 111.3 in 2020, this long-term demographic profile still makes China the most genderimbalanced country in the world (Golley and Tyers 2014). Due to China's huge population, the high SRB translates into substantial numbers of "missing women" and "excess males" across all realms of society. The resulting male marriage squeeze can be associated with such social problems as the rising cost of bride price, problems of old-age support with enormous economic pressure for those who never married, and increasing crime rates related to prostitution and trafficking in women (Jiang et al. 2011).

Given the attention being paid to the adverse consequences of gender imbalance for social development, Chinese governments at all levels have implemented comprehensive interventions since 1996. Scholars summarize these governmental interventions as "gender imbalance governance", which refers to government-led social management activities that adopt public policies and other governance means to mitigate the traditional culture of son preference, reduce the abnormally high SRB, and achieve gender equality in the whole society (Li et al. 2013). The National Population and Family Planning Commission (NPFPC, renamed the National Health Commission in 2018) is the entity tasked with governance of gender imbalance in China. 
Previous research on gender imbalance governance in China has focused mainly on policy responses and strategic actions, i.e., how to halt and reverse the biased SRB. Treating SRB as the sole indicator, however, is an inadequate approach to evaluating governance performance ( $\mathrm{Li}$ et al. 2013), and measuring governance performance as subjective performance can provide valuable information about the administration (Mizrahi et al. 2010). Here we define "governance performance of gender imbalance" as improving the perceived quality of family planning services in the governance process through which son preference is mitigated. This definition conceptually links the quality of a process with the quality of outcomes.

In 1978 the "reform and open up" policy transformed the state-society relationship in China. Over the last 40 years, Chinese public administration reform benefited greatly from the theories of governance and new public management introduced in the late 1980s as well as experiences of Western countries. It is generally agreed that the reform began with criticizing "the traditional state-centered governance paradigm to establish a new citizen-centered governance paradigm" (Xue and Zhong 2012, p. 287). In 2007, the Chinese central government established a new guiding framework led by the Chinese Communist Party and the state, under which the interests of citizens are protected, and innovation in social management is strengthened by mobilizing the population to participate in social governance and public services (Liu 2014; Yang et al. 2016). In China, public participation is relatively undeveloped, although public participation in governance is in line with the trend in governance reform, and the relationship between public participation and governance performance has been one of the focal points of academic and policymaking communities.

Public governance in China is gradually trying to develop into a kind of horizontal structure by providing channels for citizens to participate directly and build trust (Bao et al. 2012). Participatory governance "has the potential to provide a framework to support the analysis and evaluation of public policy evolution" (Osborne 2006, p. 384). The theoretical argument central to participatory governance is the "participation thesis", emphasizing the importance of public participation, including participatory villager selfgovernance and involvement in social organization, which helps build trust and improve governance performance. Governance of gender imbalance is a boundary-spanning public issue, which cannot be solved by one actor alone but requires collaboration between multiple stakeholders. Boundary-spanning stresses the increase in social capital, which is an important driver for the emergence and sustainment of collaboration (Nooteboom 2002). Trust as part of social capital is a prerequisite for public policy. Thus, a trust-based participatory paradigm is proposed.

In participatory governance, "the interaction between mechanism and context is what determines the outcome" (Falleti and Lynch 2009, p. 1151). Specifically, the outcome of the causal mechanism begins with a critical juncture, which is situated at the point of some exogenous shock (war, depression, etc.). Williamson (1999) claims that risks and uncertainties should be taken into account to some extent when designing governance. The advent of a high-risk society, i.e., a hyper-accelerated change in the number and magnitude of risks, jeopardizes governance performance (Huang and Zhu 2015). In the present study, we treat the gender-imbalanced risk society as the exogenous shock, which has contributed to weakening public confidence in family planning services.

In summary, risk, trust, and control are the underlying ingredients of public governance (Nooteboom 2002). Trust-based participatory governance is a viable model with which to study the governance of gender imbalance in China and provides a new perspective for research on governance performance. Although empirical studies of public participation and governance performance are well represented in democracies, such research in China is at the very beginning stage. This study responds to the growing call for a more systematic approach to understanding this relationship in authoritarian countries. Moreover, although scholars agree that it is normatively desirable to engage the public in governance and emphasize the importance of public participation (Neshkova and Guo 2012), there is 
still no consensus on mechanisms that specify exactly why and how public participation is expected to enhance governance performance.

This study not only specifies and clarifies hypothesized causal mechanisms between public participation and governance performance but also identifies the contextual conditions under which public participation may lead to better (or worse) performance in China. We address three key questions. First, can public participation among citizens who receive family planning services improve the governance performance of gender imbalance? Second, what role does trust play in the relationship between public participation and the governance performance of gender imbalance? Third, what role does the risk perception of gender imbalance play in the relationship between public participation and the governance performance of gender imbalance?

\section{Literature Review}

\subsection{Governance of Gender Imbalance in China}

China's gender imbalance is the most urgent strategic and livelihood issue facing the nation for population-related sustainable social development (Loh and Remick 2015). It also has an important impact on international security in Asia. Generally, there are two goals for the governance of gender imbalance: one is directed toward the causes, while the other is aimed at the consequences. In China, most interventions on gender imbalance until now have aimed primarily at the causes, and it has been widely accepted by scholars that the major direct cause of gender imbalance is accessibility to sex identification techniques (Chen et al. 2013; Nie 2010). Therefore, in the early 1990s, state and local governments focused on reducing "two illegalities", namely sex identification and sexselective abortions for non-medical purposes (Li et al. 2013). Nevertheless, the SRB has continued to increase through the 2000s, suggesting that these strict interventions have yet to be effective (Guo et al. 2016).

Numerous studies have documented that the root cause of gender imbalance is the entrenched preference for sons, which does not appear to be influenced much by rigid control (Murphy 2014). In March 2003, a government-guided campaign entitled "Care for Girls" was launched in 24 counties with the aims of eliminating gender discrimination and guaranteeing the rights of girls and women. The results have been encouraging, and this campaign eventually developed into a national strategic platform. Policies and activities adopted were piggy-backed onto family planning services, and gender imbalance governance has been institutionalized into the routine work of family planning. The primary goal of family planning services is to provide reproductive health services throughout the life course. "Advocacy" is another important activity of family planning services, focusing on publicity concerning gender equality and cultural innovation. Benefit-oriented family planning services via the system that assists families in family planning have achieved a good outcome in the attenuation of son preference and the decline of SRB (Li et al. 2013).

Citizens' evaluations of family planning services should reflect the quality of gender imbalance governance. Son preference is a form of personal interest rooted in a collective culture; it is goal-directed and context-dependent. The South Korean case sheds light on the role of public policy in reducing son preference. This "performance thesis" argues that citizens perceiving a higher level of quality in family planning services are less inclined to insist on son preference.

\subsection{Public Participation}

Since the 1950s, governments at all levels have initiated programs of public participation, with the underlying presumption that if citizens actively participate in policymaking and democracy, policies that are formulated as a result of this process will be more realistic, and the resulting governance will be more democratic and effective (Irvin and Stansbury 2004). A conceptual framework for participatory governance has been developed and continues to be used (Emerson et al. 2012; Newig et al. 2018). The effectiveness of participa- 
tory governance has been demonstrated consistently and strongly in research on public administration.

Increasing public participation is a potent means of achieving effectiveness, accountability, and responsiveness of governance under democracy (Fung 2015; Heikkila and Isett 2007). It does this by building trust and facilitating mutual understanding because public participation can create collective norms of reciprocity (Fischer 2015). In other words, "it fulfills the three basic human needs: increased autonomy, increased meaningfulness, and decreased isolation" (Sashkin 1984, p. 11). Cuthill and Fien (2005) argue that significant community development rests on the commitment of community members to invest themselves and their resources in the effort. In view of this, public participation is of crucial importance in explaining governance performance (Seller 2017).

The concept of public participation is related to the rights of citizenship and governance. Wang and Wan Wart (2007) define public participation as a direct or indirect public involvement in governance. Gao (2014) divides public participation in China into two dimensions: civic autonomy and organizational involvement. Civic autonomy, i.e., villager self-governance, can be seen as an umbrella term for direct participation in governance, such as citizen engagement, civic participation, and participatory democracy (Siebers et al. 2019). Civic autonomy aims to make better decisions, thereby providing more efficient benefits to the whole society (Irvin and Stansbury 2004). Organizational involvement refers to interaction in horizontal non-hierarchical networks. Collective endeavors can arise when local citizens are involved in social structures and practices dedicated to common interests and goals (Putnam et al. 1993). In particular, skills of civic literacy and moderate political attitudes may be instilled as opposing pressures by civil associations, forcing members of diverse groups to collaborate (Andrews 2007).

In China's governance of gender imbalance, the majority of public interventions are initiated, implemented, and monitored by the government. As a result, civil society plays a small role in decision making, management, and monitoring. However, civil society is an important stakeholder in public governance. To our knowledge, little research has been carried out on the relationship between public participation and governance performance.

\subsection{Trust}

Governance of gender imbalance in China aims to tackle the tension between collective and individual interests. Sex identification practice driven by son preference provides a vehicle for opportunism. Trust acts as an effective instrument of governance for developing a departure from opportunism. An essential function of trust is to inhibit opportunistic behavior and reduce relational risk. Trust is a multidimensional concept based on positive expectations and generally falls into two categories: interpersonal trust and institutional trust (Nooteboom 2002). Institutional trust captures the confidence in institutions and public administration. If citizens trust government authorities, they are more likely to comply with their directives. The governance of gender imbalance is under the influence of the state, directly through family planning services and indirectly through promulgation of laws; thus, governance processes are more likely to succeed when participants trust the government (Welter and Smallbone 2011).

In a collectivistic and relationship-oriented society, interpersonal relationships are vital to public service effectiveness. Interpersonal trust can complement institutional trust. Strongly linked to social ties, interpersonal trust is therefore divided into generalized trust and particularized trust, the former refers to trust in strangers beyond one's own group or network (weak ties), and the latter refers to trust in people from one's own group (strong ties) (Suebvises 2018). Interpersonal trust is defined by Fukuyama (1995) as the expectation that arises within a community when other people behave in predictable, honest, and cooperative ways. In China, community-based networks and organizations have become important reference groups (Chen 2000). To achieve efficient outcomes and to avoid inefficient "non-cooperative traps", such as the prisoners' dilemma, people in a 
community tend to cooperate (Chen et al. 2011). Therefore, this study uses social trust in the community or village to elucidate governance performance.

However, theoretical and empirical progress on the role of trust in public governance has been modest because "the theoretical underpinnings are poorly defined and most studies rely on single-factor analyses" (Wang and Wan Wart 2007, p. 266).

\subsection{Risk Perception}

We have become a risk society in which we are all equally vulnerable. Additionally, increased self-monitoring in contemporary society leads to a constant perception of risks (Giddens 1991). In rural China, gender imbalance is a "structural risk", preventing threats to human life (Klinke 2021), and increasingly perceived as a high-risk issue by villagers through direct experience and extensive media coverage; it is manifested in male marriage squeezes, missing females, and related social problems such as the rising cost of bride price, increasing prostitution, and abduction of and trafficking in women. The increasingly significant risks arising from gender imbalance pose challenges to the governance of gender imbalance.

In the context of risk society, demands for greater public participation have emerged in policy circles. Public participation is used to inject and integrate various values and demands into governance, making more socially acceptable decisions and improving the quality of services. "Public engagement, however cannot guarantee positive outcomes" (Mah et al. 2014, p. 370). The general assumption that disasters often have negative political effects (Carlin et al. 2013) emphasizes that risks intertwined with public participation have at least some effect on how citizens perceive their government's performance (Albrecht 2017). To date, little attention has been paid to the risks of gender imbalance in the evaluation of either policy implementation or performance.

\section{Conceptual Model and Hypotheses}

Figure 1 shows the conceptual model of this study, which adopts a simple yet theoretically concise method to explain the relationships between public participation, trust, risk perception, and governance performance. Informed by the causal mechanisms of participatory governance (Newig et al. 2018), relating participation to outputs, the theoretical framework consists of two sub mechanisms: internal condition and external context. First, the key theoretical argument regarding participatory governance originates from the principal-agent theory. Mechanisms of participatory governance can help to overcome the agency problem, thus improving provision and outcomes of services. Second, a high level of trust, as an internal condition, is desirable and can stimulate positive outcomes. Third, valid causal inference requires contextualizing the participatory governance mechanism. Risk society, as an exogenous shock, may promote or inhibit the role of public participation, which is crucial for the validity of the mechanism. 


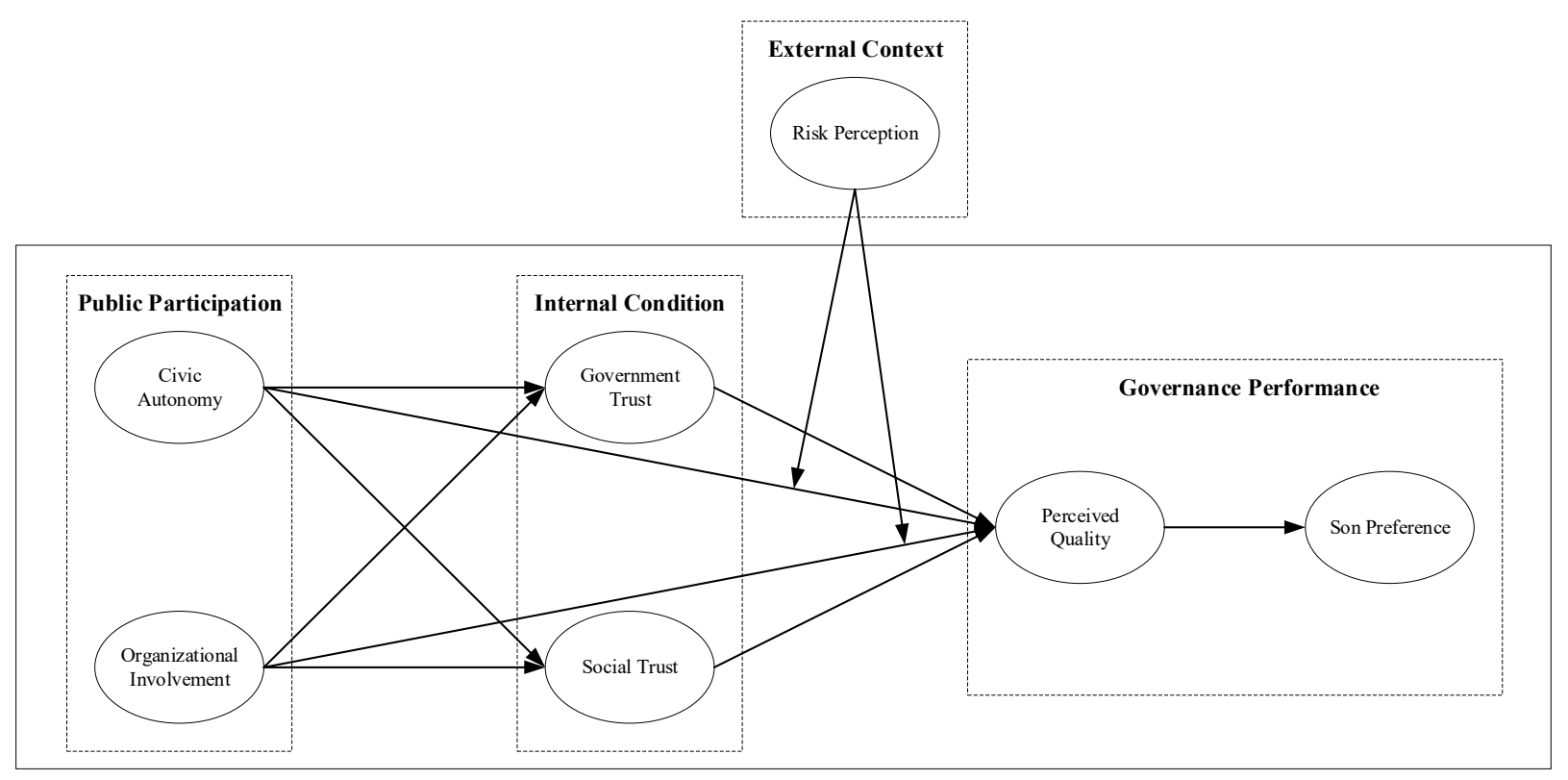

Figure 1. Conceptual model.

\subsection{The Role of Public Participation}

Defined as engagement and involvement in public affairs and social activities, public participation has been widely documented as a necessary means to enhance governance performance, illustrated by proponents of new public administration (Andrews and Brewer 2013; King et al. 1998; Michels 2011; Mizrahi et al. 2009, 2010; Putnam 2000). Public participation can incorporate knowledge and values, helping articulate demands and elicit preferences (Beeri et al. 2019), which, in turn, make it easier for governments to meet citizens' needs. It is particularly relevant for family planning services, which are humancentered services having a universal impact and which have been implemented over the past decades to mitigate son preference (Kumar and Sinha 2020).

Civic autonomy is conceptualized as citizens' direct participation in governance. Through sharing in governance, citizens and administrators can choose actions that gradually reshape public services. It has been corroborated in Western democracies that citizen participation has a discernible effect on public service performance. Neshkova and Guo (2012) find that citizen participation in administrative decision making is positively related to greater efficiency and effectiveness of public services. This was subsequently supported by Speer (2012) and Owen (2020), who delineated participatory governance in developing and authoritarian countries, emphasizing the importance of civic autonomy. He and Ma (2020) note that citizen participation in health policy generates positive outcomes in Hong Kong, i.e., higher perceived performance. Thus, civic autonomy is expected to promote the performance of public services.

Organizational involvement can supplement and support civic autonomy as indirect participation. Putnam et al. (1993) posit that associational life relates directly to public sector performance in terms of efficacy. Community organizational life (such as sports clubs) expose local citizens to diverse ideas and experiences, which may encourage the development of shared norms and concerns through interaction in social networks (Andrews and Brewer 2013). Citizens involved in organizations can help frame the particular problem, for instance, gender imbalance in this study, in more accurate ways than governments acting alone (Fung 2015). Community organizations therefore generate positive externalities for public organizations, thus enhancing public service performance.

This study identifies two tiers of metrics to be taken into account when evaluating the governance performance of gender imbalance: process-oriented (the perceived quality of family planning services) and outcome-oriented (son preference). The "performance 
thesis" mentioned above constitutes the basic logic of governance performance; that is, son preference is mitigated through family planning services. We therefore argue that participating citizens are likely to evaluate the quality of family planning services positively and be less inclined to insist on son preference.

Hypothesis 1 (H1). Civic autonomy will significantly increase the perceived quality of family planning services, which, in turn, leads to weak son preference.

Hypothesis 2 (H2). Organizational involvement will significantly increase the perceived quality of family planning services, which, in turn, leads to weak son preference.

\subsection{The Mediating Role of Trust}

The mechanism by which effective public participation helps restore trust, thus strengthening accountability and policy legitimacy (He and Ma 2020), underlies the mediating role of trust, which has been partially examined in some studies (Lim et al. 2016). Public participation may strengthen the sense of group identity and correspondingly trust in government and others, thus enhancing the perceived performance of public services (Mizrahi et al. 2010).

Specifically, there is a remarkable convergence around the proposition that public participation boosts trust in government (Hu et al. 2015; Kim and Lee 2012; Shim and Park 2016), although some scholars emphasize the reverse causality (Lee and Schachter 2019). For normative and instrumental reasons, public participation, "both on the organizational/bureaucratic level and on the communal/political level, may increase trust in governance and potentially in administrative agencies because they enhance the information citizens have about various processes and their identification with policies and outcomes" (Mizrahi et al. 2009, p. 8). On the other hand, trust in government is increasingly found in public service literature as a pivotal factor in improving performance (Ma and Christensen 2019; Nyhan 2000). Citizens who trust the government are more likely to be pleased by public policies.

Apart from government trust, a number of studies provide empirical evidence that public participation boosts social trust (Huhe et al. 2015; Eopaciuk-Gonczaryk 2019; Suebvises 2018). Interaction among participants, whether in public affairs or social activities, potentially produces greater social trust through the exchange of diverse perspectives and knowledge conducive to mutual learning (Heikkila and Gerlak 2013). Moreover, the social capital literature posits that social trust facilitates agreement where preferences are polarized, which helps forge convergence and cooperation, providing favorable conditions for positive outcomes (Huhe et al. 2015; Oh and Bush 2014; Suebvises 2018). In light of this, interpersonal trust can improve compliance with public services, thereby increasing the perceived quality.

To sum up, trust is, in part, initiated by public participation, and in that sense, it is an intermediate outcome or a mediator that produces better governance performance. Participating citizens are more likely to evaluate public services positively when they trust the government and other people. Thus the following hypotheses are proposed:

Hypothesis 3 (H3). Government trust will play a significant mediating role in the relationship between civic autonomy and the perceived quality of family planning services.

Hypothesis 4 (H4). Government trust will play a significant mediating role in the relationship between organizational involvement and the perceived quality of family planning services.

Hypothesis 5 (H5). Social trust will play a significant mediating role in the relationship between civic autonomy and the perceived quality of family planning services.

Hypothesis 6 (H6). Social trust will play a significant mediating role in the relationship between organizational involvement and the perceived quality of family planning services. 


\subsection{The Moderating Role of Risk Perception}

Although public participation is viewed as enhancing governance performance, there may be contexts where this expectation does not hold. This study seeks to account for the external context of the gender-imbalanced society in rural China, where gender imbalance is an element that produces risk (Eklund 2018). For stakeholders, perceptions are a reality, which "play a major role in motivating individuals to take action to avoid, mitigate, adapt to, or even ignore risks" (Poetz 2012; Wachinger et al. 2013, p. 1050). Whether in the face of natural hazards or human-made emergencies, citizens with high-risk perceptions will choose to personally prepare themselves, i.e., behave adaptively. The perceived risk may interact with public participation in predicting performance.

Risk perception is domain-specific and thus has a paradoxical relationship with civic autonomy. As for risks that fundamentally depend on government control, highrisk perception provides citizens with the motivation to engage in public governance to reduce the risks ( $\mathrm{Xu}$ et al. 2020). However, for risks that diffuse across society, risk perception has a significantly negative impact on civic autonomy, indicating that high-risk perception does not trigger villagers to choose positive political behavior in order to avoid risk (Xie 2013). The latter scenario suggests that as risk perception of gender imbalance increases, individuals will focus on improving their resources and capabilities to respond to risks rather than participating in governance, which may spill over into the evaluation of public services, undermining the perceived quality.

Moreover, the effect exerted by organizational involvement on the perceived quality of public services is also shaped by risk perception. On the one hand, perceived risk is amplified by interpersonal discussion among local citizens in community-based organizations (Binder et al. 2011). Citizens struggle to protect their own benefits, which leads to competition for public services. On the other hand, the plurality of interests and demands may evoke conflicts and shatter citizens' confidence in public services (Klinke 2021). This suggests that risk perception may dampen the positive influence of organizational involvement on perceived quality.

Accordingly, it is reasonable to hypothesize that in a risk society with a severe gender imbalance, risk perception, acting as a moderator, curtails the influence of public participation on perceived quality. The links between public participation and perceived quality may be less pronounced when risk perception is stronger.

Hypothesis 7 (H7). Risk perception of gender imbalance will negatively moderate the positive effect of civic autonomy on the perceived quality of family planning services.

Hypothesis 8 (H8). Risk perception of gender imbalance will negatively moderate the positive effect of organizational involvement on the perceived quality of family planning services.

\section{Materials and Methods}

\subsection{Data Collection}

To test these hypotheses, we designed a questionnaire and conducted a survey in August 2018. The data were collected from 20 villages and communities in Hubei province, China. It is important to present some background of the sample province to clarify why we regard Hubei as an ideal case for exploring the relationship between public participation and governance performance of gender imbalance. Hubei is a landlocked province in Central China that has been the focus of national comprehensive governance of the high SRB in China. Since becoming one of the three pilot provinces in UNFPA's Government of China Eighth Country Programme (2016-2018), Hubei has begun to promote gender mainstreaming, changing social norms, culture, and customs of son preference and emphasizing multi-sectoral participation in governance. Villages/Communities and families are treated as basic actors and entry points of intervention to enable societal change. Engagement of villages/communities, public participation, and bottom-up changes in the traditional rural gender culture are crucial to eliminating son preference (UNFPA and CPDRC 2018). 
Villages and communities were chosen as units of the study because the public is geographically closer to local government than the central government and because public participation and trust at the local level are more easily perceived and measured.

The survey randomly sampled various villages/communities based on the size and structure of their populations to ensure that each village/community was represented in the sample proportionately to its population. A total of 1032 survey questionnaires were distributed among the 20 villages/communities. The respondents' average age was $42.38(\mathrm{SD}=9.29)$, with an average of 9.38 years of education $(\mathrm{SD}=3.17)$ and an average of $25,073$ yuan of annual income (SD $=32,515) .53 .88 \%$ of the respondents identified as female and $91.28 \%$ were married. Table 1 shows the demographic characteristics of the samples.

Table 1. Demographic profile $(\mathrm{N}=1032)$.

\begin{tabular}{ccc}
\hline Respondent Profiles & Frequency/Mean & Percentage/SD \\
\hline Age & 42.38 & 9.29 \\
\hline Gender & & \\
Male & 476 & 46.12 \\
Female & 556 & 53.88 \\
\hline Marital status & & \\
Unmarried & 90 & $8.72 \%$ \\
Married & 942 & $91.28 \%$ \\
\hline Education (years) & 9.38 & 3.17 \\
\hline Annual income (yuan) & 25,073 & 32,515 \\
\hline
\end{tabular}

\subsection{Measurements}

The survey consists of seven constructs with a total of 39 items. These are described below and listed in Appendix B.

\subsubsection{Governance Performance of Gender Imbalance}

The complexity of governance performance in the public sector is a hot topic that has long been debated in the public management literature (Andrews et al. 2011). Chen et al. (2011) point out that perceived performance has become the optimal quantitative index. Good government in a democracy depends on positive citizen evaluation, which may be entirely subjective (Kweit and Kweit 2004). Although perceptual measures pose a number of problems, previous studies have supported their validity by showing that subjective and objective measures of governance performance are highly correlated (McCracken et al. 2001). Governance performance of gender imbalance is measured by subjective evaluation, consisting of the perceived quality of family planning services and son preference.

While measuring perceived quality remains difficult, two key dimensions suggested by Putnam et al. (1993) are commonly used by scholars: responsiveness and effectiveness (Xia 2011). As the assessment of governance performance moves from government-centric to public-centric, citizen satisfaction and service reliability are also important indicators (Zhang and Hu 2014). Perceived quality of family planning services is rated using four dimensions from the Service Evaluation Questionnaire (SEQ) developed by Nguyen et al. (1983): attitudes toward the general responsiveness and effectiveness of governance; and detailed evaluations of respondents' satisfaction with and reliability of governmental services. We modified this scale to apply to family planning services by adjusting the service content. Each item uses a four-point Likert scale ranging from 1 (No, Definitely not) to 4 (Yes, Definitely).

Son preference is deeply ingrained in patrilineal societies, where patriarchal institutions and norms place greater value on sons than daughters. It is measured by the following items based on the value of sons on a scale from 1 (strongly disagree) to 5 (strongly agree): old-age support, financial support, day-to-day care, carrying on the family lineage and prestige, emotional support. 


\subsubsection{Public Participation}

Public participation refers to the deep and continuous engagement of the citizenry in the administrative processes, where all involved are likely to have an impact on the situation (King et al. 1998). In this study, it is defined as individual involvement in administrative functions and village/community activities. Therefore, public participation is gauged by two indices: civic autonomy and organizational involvement.

Civic autonomy is defined as "direct democracy" or "rule by the people", which involves actions aimed at resolving problems of the village or community at the local level (Zukin et al. 2006). It is measured with three indicators based on the participation behavior scale developed by Xie and Zhang (2013). Each item uses a four-point Likert scale ranging from 1 (never) to 4 (often).

Organizational involvement refers to participation in specific activities (Somma 2010). It is measured by one subscale adopted from the Chinese General Social Survey (CGSS): "In your spare time, have you participated in the following activities of social organizations?" According to the types of social organization activities, this item includes seven items (fitness/sports activities, entertainment activities, social activities, religious activities, activities that help to develop/educate children's abilities, activities that help improve individual skills/techniques, charitable/compulsory activities). Respondents indicate whether they have or have not participated in each activity rated on a five-point Likert scale. The coding scheme is as follows: 1 (never), 2 (several times a year), 3 (once a month), 4 (once a week), 5 (several times a week).

\subsubsection{Trust}

Trust in government can be evaluated by the extent to which citizens have confidence in the local government that directly responds to and handles gender imbalance. A set of five items was developed by Shim and Park (2016) and adapted to measure government trust. The respondents were asked to indicate the degree of trust in the following items on a scale from 1 (very low trust) to 5 (very high trust): institution (the village/community), governance resources, public services, information, and staff.

Social trust can be conceptualized as perceived trustworthiness, which indicates that people expect support and believe that there is a relationship in which issues can be discussed, and interdependence can be established (Ferrin et al. 2006). This study defines social trust as interpersonal mutual trust within a community/village, where the respondent is both a trustor and a trustee (Six et al. 2010). It is measured by six items modified from the world values survey (WVS). All assessments are measured on a fivepoint Likert scale ranging from 1 (strongly disagree) to 5 (strongly agree).

\subsubsection{Risk Perception of Gender Imbalance}

Risk perception is the "process of collecting, selecting, and interpreting signals about uncertain impacts of events or activities" (Wachinger et al. 2013, p. 1049). The data set used in this study includes a group of items on public perceptions of gender imbalance risks. The respondents were asked: "What do you think of the following statements related to gender imbalance?" The nine risks listed are high marriage expenses, many unmarried males over 30 years old, trafficking in women and children, safety issues for left-behind women and children, extramarital relationships, irregular marriages (such as mercenary marriage and early marriage), increasing crime rate due to more unmarried men, forced bachelor families face enormous economic pressure, forced bachelor families face problems of old-age support. The risk perception was rated on a five-point Likert scale ranging from 1 (strongly disagree) to 5 (strongly agree).

\subsection{Analytic Methods}

Structural equation modeling (SEM) and moderated multiple regressions (MMR) were used to assess the hypothesized relationships, as shown in Figure 1. SEM is a statistical technique that combines factor analysis to evaluate the reliability and validity of 
the measurement model and multiple regression to validate the relationships among the theoretical constructs (Kline 2016). It is particularly valuable in analyzing measurement and structural models with multi-item constructs and is more versatile than most other multivariate analytic tools; thus, it is widely used for performance research in the public sector (Morgeson et al. 2011). The overriding virtue of SEM is its ability to correct for measurement error by allowing the researcher to specify the estimated error between the survey data (manifest variables) and the theoretical constructs (latent variables) designed to measure (Nyhan 2000).

Specifically, confirmatory factor analysis (CFA) was employed to evaluate the quality of the measurement model and should be conducted prior to testing the structural model. Based on the modified measurement model, structural equation modeling was applied to validate the hypothesized relationships of the structural model, where parameters were estimated by the most widely used fitting technique, i.e., maximum likelihood (ML), under the assumption that data are missing at random (Kim and Lee 2012). To test the hypothesis about trust as a mediator, we used the bootstrap for testing indirect effects. SEM is considered to be more rigorous than typical stepwise regression as all mediation paths are measured and estimated simultaneously rather than being restricted to an additive model (Garson 2013). To test the moderating effect of risk perception, moderated multiple regressions were performed, taking perceived quality as the dependent variable (Aiken and West 1991). Before generating the interaction terms, we mean-centered the variables. Data analyses were performed using SPSS 22.0 (IBM Corp., Armonk, NY, USA) and Mplus 7.0 (Muthén \& Muthén, Los Angeles, CA, USA).

The generally recommended and used practical fit indices to appraise the fit of the entire model are $\chi^{2} / \mathrm{df}$ (chi-square goodness of fit index), CFI (comparative fit index), TLI (Tucker Lewis index), RMSEA (root mean square error of approximation), and SRMR (standardized root mean square residual). The traditional criterion for the value of $\chi^{2} / \mathrm{df}$ is smaller than 3. CFI and TLI values equal to or greater than 0.90 are considered acceptable (Hu and Bentler 1995). From Browne and Robert (1993), a value of RMSEA between 0.05 and 0.08 can be considered to represent an adequate fit. As a rule of thumb, the SRMR should be lower than 0.05 (Hu and Bentler 1995).

\section{Results}

\subsection{Reliability and Validity}

In this study, there are seven measurement models, one for each latent construct. To achieve identifiability, we fixed the variance of each factor at 1.0. Appendix B displays Cronbach's alpha, survey items, and the factor loadings for each scale. Cronbach's alpha coefficients are used to measure the internal consistency of these multivariate scales, and the values for civic autonomy, organizational involvement, government trust, social trust, risk perception, perceived quality, and son preference scales were $0.869,0.823,0.791,0.838$, $0.815,0.751$, and 0.889, all greater than 0.75 (Nunnally and Bernstein 1994), which indicate strong reliability for the survey instrument.

To analyze content validity, CFA was performed on all the above items for structural equation modeling. Each of the factor loadings on their respective latent factor is significant. Overall measures of model fit such as $\chi^{2} / \mathrm{df}$ (2.21), CFI (0.936), TLI (0.931), and RMSEA (0.034) are acceptable, which suggests that the proposed CFA model can serve as a valid measurement model. Items with factor loadings below 0.45 are deleted. Except for two items, religious activities and high marriage expenses, all of the coefficients are aboverecommended thresholds. Involvement in religious activities and high marriage expenses were considered unimportant to the model and were therefore deleted, leaving six items for organizational involvement and eight items for risk perception for subsequent analysis.

\subsection{Testing for Direct Effect}

The high alpha values of each scale indicate the validity of using an average of the items to serve as the measure of civic autonomy (CA), organizational involvement (OI), 
government trust (GT), social trust (ST), perceived quality (PQ), and son preference (SP). Table 2 records the value of the means and standard deviations of the constructs, as well as zero-order correlations for all of the variables. All of the correlations are in the expected directions, indicating initial support for the relationships depicted in Figure 1. Consistent with expectations, public participation is positively associated with trust and perceived quality and negatively correlated with son preference. Perceived quality of family planning services is negatively associated with son preference. Trust is positively associated with perceived quality.

Table 2. Means, standard deviations, and correlations $(\mathrm{N}=1032)$.

\begin{tabular}{ccccccccc}
\hline & Mean & SD & CA & OI & GT & ST & PQ & SP \\
\hline CA & 2.03 & 0.93 & 1 & & & & & \\
OI & 2.07 & 0.80 & $0.391^{* * *}$ & 1 & & & & \\
GT & 3.86 & 0.61 & $0.341^{* * *}$ & $0.273^{* * *}$ & 1 & & & \\
ST & 3.83 & 0.59 & $0.203^{* * *}$ & $0.160^{* * *}$ & $0.353^{* * *}$ & 1 & & \\
PQ & 3.06 & 0.55 & $0.352^{* * *}$ & $0.297^{* * *}$ & $0.427^{* * *}$ & $0.275^{* * *}$ & 1 & \\
SP & 2.59 & 0.94 & $-0.098^{* *}$ & $-0.105^{* * *}$ & $-0.072^{*}$ & -0.059 & $-0.148^{* * *}$ & 1
\end{tabular}

Notes: ${ }^{* * *} p<0.001 ;{ }^{* *} p<0.01 ;{ }^{*} p<0.05$; two-tailed tests. CA = civic autonomy, OI = organizational involvement, $\mathrm{GT}=$ government trust, $\mathrm{ST}=$ social trust, $\mathrm{PQ}=$ perceived quality, $\mathrm{SP}=$ son preference

For the structural model, the $\chi^{2} / \mathrm{df}$ is $3.00(1098.542 / 366)$, the CFI is 0.940 , the TLI is 0.933, the RMSEA is 0.044 (90 percent confidence interval: $0.041,0.047$ ), and the SRMR is 0.035. All the parsimonious fit indexes support the proposed structural model. Considering the sample size, this entire conceptual model is found to fit the data.

Figure 2 reveals that the hypothesized relationships between public participation, trust, and governance performance are supported by the results. Both civic autonomy and organizational involvement are positively related to the perceived quality of family planning services, which, in turn, significantly decreases son preference. The standardized coefficients show that the impact of civic autonomy on perceived quality is greater than that of organizational involvement. Thus, hypotheses $\mathrm{H} 1$ and $\mathrm{H} 2$ are supported.

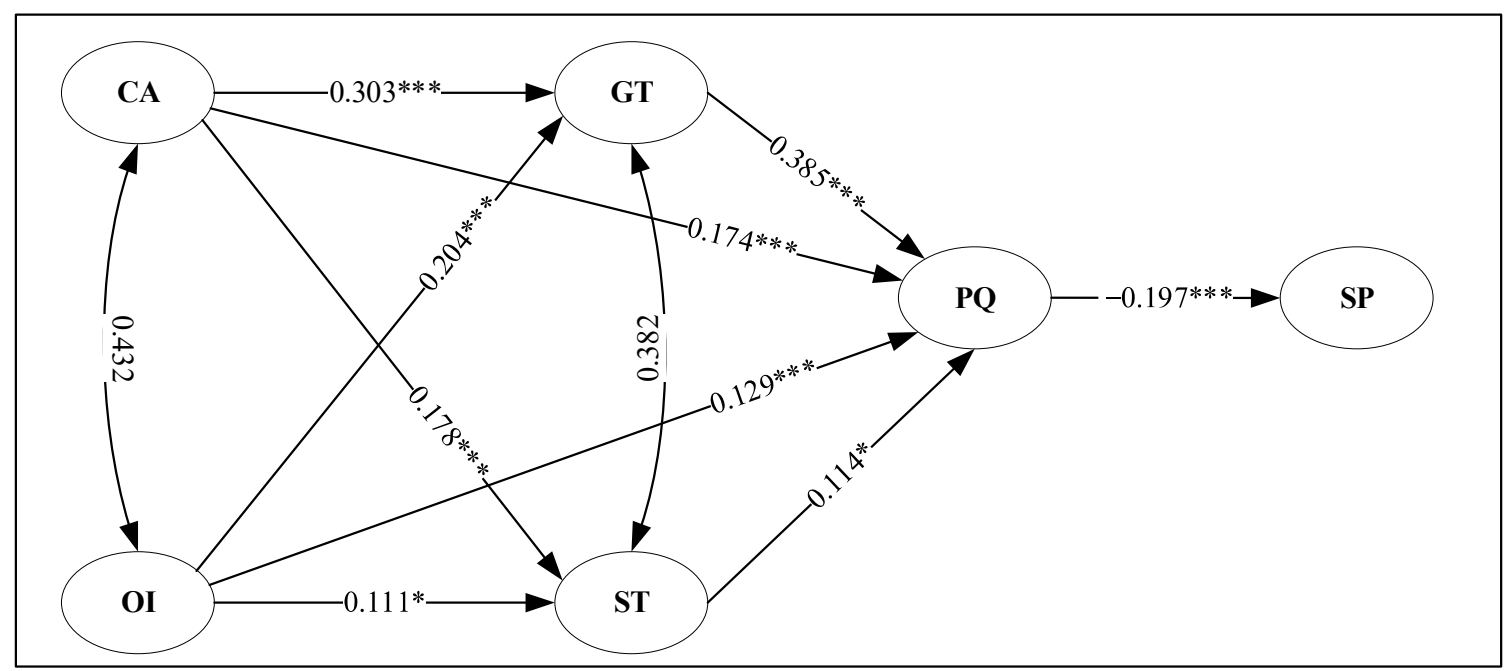

Figure 2. Results of the structural equation model. Notes: ${ }^{* *} p<0.001 ;{ }^{*} p<0.05$; see Appendix A for the equation. $\mathrm{CA}=$ civic autonomy, $\mathrm{OI}=$ organizational involvement, $\mathrm{GT}=$ government trust, $\mathrm{ST}=$ social trust, $\mathrm{PQ}=$ perceived quality, $\mathrm{SP}=$ son preference.

\subsection{Testing for Mediation Effect}

With regard to the mediating role of trust, Hypotheses $\mathrm{H} 3, \mathrm{H} 4$, and $\mathrm{H} 5$ are supported by the statistical results shown in Figure 2 and Table 3, but Hypothesis H6 is not. Trust is positively influenced by public participation and is associated with higher perceived 
quality. Government trust mediates the relationship between public participation (both civic autonomy and organizational involvement) and the perceived quality of family planning services, while social trust only exerts a mediating effect between civic autonomy and perceived quality. Going further, the serial mediation effect of civic autonomy and organizational involvement on son preference through government trust and perceived quality is significant. Taken as a whole, public participation positively influences trust, government trust in particular, which in turn positively affects perceived quality and finally attenuates son preference.

Table 3. Bootstrapping indirect effect of trust.

\begin{tabular}{|c|c|c|c|c|c|c|c|c|}
\hline & \multirow{3}{*}{\multicolumn{2}{|c|}{ Indirect Effect }} & & \multirow{3}{*}{ Estimate } & \multirow{3}{*}{ S.E. } & \multicolumn{3}{|c|}{ Bootstrapping } \\
\hline & & & & & & \multicolumn{2}{|c|}{$95 \%$ CI } & \multirow{2}{*}{$p$-Value } \\
\hline & & & & & & LLCI & ULCI & \\
\hline $\mathrm{CA} \rightarrow$ & $\mathrm{GT} \rightarrow$ & PQ & & 0.117 & 0.019 & 0.079 & 0.154 & 0.000 \\
\hline $\mathrm{CA} \rightarrow$ & $\mathrm{GT} \rightarrow$ & $\mathrm{PQ} \rightarrow$ & SP & -0.023 & 0.006 & -0.034 & -0.012 & 0.000 \\
\hline $\mathrm{OI} \rightarrow$ & $\mathrm{GT} \rightarrow$ & PQ & & 0.079 & 0.018 & 0.043 & 0.114 & 0.000 \\
\hline $\mathrm{OI} \rightarrow$ & $\mathrm{GT} \rightarrow$ & $\mathrm{PQ} \rightarrow$ & SP & -0.015 & 0.005 & -0.025 & -0.006 & 0.002 \\
\hline $\mathrm{CA} \rightarrow$ & $\mathrm{ST} \rightarrow$ & $\mathrm{PQ}$ & & 0.020 & 0.010 & 0.002 & 0.039 & 0.034 \\
\hline $\mathrm{CA} \rightarrow$ & $\mathrm{ST} \rightarrow$ & $\mathrm{PQ} \rightarrow$ & SP & -0.004 & 0.002 & -0.008 & 0.000 & 0.059 \\
\hline $\mathrm{OI} \rightarrow$ & $\mathrm{ST} \rightarrow$ & PQ & & 0.013 & 0.008 & -0.003 & 0.029 & 0.116 \\
\hline $\mathrm{OI} \rightarrow$ & $\mathrm{ST} \rightarrow$ & $\hat{\mathrm{PQ}} \rightarrow$ & SP & -0.003 & 0.002 & -0.006 & 0.001 & 0.145 \\
\hline
\end{tabular}

Note: CA = civic autonomy, OI = organizational involvement, GT = government trust, ST = social trust, $\mathrm{PQ}=$ perceived quality, $\mathrm{SP}=$ son preference.

\subsection{Testing for Moderation Effect}

Two interaction terms, $\mathrm{CA}^{*} \mathrm{RP}$ and $\mathrm{OI}{ }^{*} \mathrm{RP}$, were created to calculate the moderating effect of risk perception on the relationship between public participation and perceived quality. The results of the moderated multiple regressions are shown in Tables 4 and 5. The evidence runs counter to hypothesis $\mathrm{H} 7$ and does not support $\mathrm{H} 8$, indicating that risk perception of gender imbalance has a significant positive moderating effect on the relationship between civic autonomy and perceived quality but has no significant effect on the relationship between organizational involvement and perceived quality.

Table 4. Regressing perceived quality on civic autonomy and risk perception.

\begin{tabular}{|c|c|c|c|c|c|c|c|c|c|}
\hline \multirow[b]{3}{*}{ Predictors } & \multicolumn{9}{|c|}{ Dependent Variable: Perceived Quality } \\
\hline & \multicolumn{3}{|c|}{ Model 1} & \multicolumn{3}{|c|}{ Model 2} & \multicolumn{3}{|c|}{ Model 3} \\
\hline & B & Beta & $\mathrm{T}$ & B & Beta & $T$ & B & Beta & $\mathbf{T}$ \\
\hline Constant & 3.063 & & $190.500^{* * *}$ & 3.06 & & $191.972 * * *$ & 3.07 & & 190.913 *** \\
\hline CA & 0.208 & 0.352 & $12.073^{* * *}$ & 0.198 & 0.335 & $11.460^{* * *}$ & 0.199 & 0.336 & $11.507^{* * *}$ \\
\hline $\mathrm{RP}$ & & & & -0.093 & -0.120 & $-4.118^{* * *}$ & -0.094 & -0.122 & $-4.185^{* * *}$ \\
\hline$C A^{*} \mathrm{RP}$ & & & & & & & 0.055 & 0.068 & 2.368 * \\
\hline F-value & $145.758^{* * *}$ & & & $82.488^{* * *}$ & & & $57.108^{* * *}$ & & \\
\hline $\begin{array}{c}\text { Adjusted } \\
\mathrm{R}^{2}\end{array}$ & 0.123 & & & 0.136 & & & 0.140 & & \\
\hline
\end{tabular}

Notes: ${ }^{* * *} p<0.001 ;{ }^{*} p<0.05 . \mathrm{B}=$ the unstandardized beta; Beta $=$ the standardized beta; $\mathrm{T}=$ the $\mathrm{t}$ test statistic. $\mathrm{CA}=$ civic autonomy, $\mathrm{RP}=$ risk perception. 
Table 5. Regressing perceived quality on organizational involvement and risk perception.

\begin{tabular}{|c|c|c|c|c|c|c|c|c|c|}
\hline \multirow[b]{3}{*}{ Predictors } & \multicolumn{9}{|c|}{ Dependent Variable: Perceived Quality } \\
\hline & \multicolumn{3}{|c|}{ Model 4} & \multicolumn{3}{|c|}{ Model 5} & \multicolumn{3}{|c|}{ Model 6} \\
\hline & B & Beta & $\mathrm{T}$ & B & Beta & $\mathbf{T}$ & B & Beta & $\mathrm{T}$ \\
\hline Constant & 3.06 & & $186.647^{* * *}$ & 3.06 & & $188.614^{* * *}$ & 3.06 & & $187.805^{* * *}$ \\
\hline OI & 0.206 & 0.297 & $9.975^{* * *}$ & 0.197 & 0.283 & $9.585^{* * *}$ & 0.196 & 0.283 & $9.551 * * *$ \\
\hline $\mathrm{RP}$ & & & & -0.109 & -0.141 & $-4.770 * * *$ & -0.110 & -0.142 & $-4.805^{* * *}$ \\
\hline $\mathrm{OI}{ }^{*} \mathrm{RP}$ & & & & & & & -0.022 & -0.025 & -0.848 \\
\hline F-value & $99.508^{* * *}$ & & & $62.183^{* * *}$ & & & $41.684^{* * *}$ & & \\
\hline $\begin{array}{c}\text { Adjusted } \\
\mathrm{R}^{2}\end{array}$ & 0.087 & & & 0.106 & & & 0.106 & & \\
\hline
\end{tabular}

Notes: $* * * p<0.001 . \mathrm{B}=$ the unstandardized beta; Beta $=$ the standardized beta; $\mathrm{T}=$ the $\mathrm{t}$ test statistic. $\mathrm{OI}=$ organizational involvement, $\mathrm{RP}=$ risk perception.

\section{Conclusions}

Although public participation has been widely recognized as an important factor in the public administration literature, most research is qualitative, focusing on the benefits of the participatory process (Neshkova and Guo 2012). There has been virtually no consensus on how public participation affects governance performance in non-democratic settings. This study is one of the few empirical attempts to explicitly explore the nexus of public participation and governance performance, using data collected from Chinese local governments. The results indicate that the proposed conceptual model adequately explains the data. Specifically, the effect of public participation on reducing son preference is largely generated by the mediating or moderating role of trust and risk perception, i.e., indirectly by the two variables rather than directly by public participation itself. A more nuanced and thorough understanding of trust-based participatory governance in authoritarian regimes has both theoretical contributions and policy implications.

\subsection{Theoretical Contributions}

We constructed a model based on the widely used participatory governance framework in Western countries that takes into consideration the contextual conditions of public governance and applied it to data concerning China's family planning services. The framework assesses the extrinsic benefits of participatory governance in authoritarian countries; that is, the potential of participatory governance to improve the quality of public service provision. This study sheds theoretical light on public participation in the governance of gender imbalance.

Public participation enhances the perceived quality of family planning services, which in turn decreases son preference, revealing that participating citizens, as consumers of government services, develop a better understanding of the inherent complexities in public issues and a greater appreciation of an administrator's job (Kathlene and Martin 1991). Our findings are consistent with those of previous studies showing that public participation is the cornerstone of good governance (Enserink and Koppenjan 2007), and effective public participation can substantively improve governance performance (King et al. 1998; Yang and Pandey 2011), especially in areas that straddle the boundaries between public and private. This study also demonstrates that engaging in civic autonomous organizations exerts a more pronounced effect on the perceived quality of family planning services than participating in social organizations, although social organizations are better at bringing together people with divergent backgrounds (Uslaner and Conley 2003).

Furthermore, this study illuminates the black box of public participation by demonstrating the mediating role of trust. Consistent with past studies, public participation is a strong predictor of trust (Shim and Park 2016; Wang and Wan Wart 2007), and trust, especially government trust, has a salutary effect on governance performance (Ma and Christensen 2019). The findings demonstrate that public participation can be regarded as a good mechanism for increasing trust, while trust is an intangible relational asset for effective governance to lay a solid foundation for the provision of public services. Additionally, 
the present study reveals that public participation indirectly promotes governance performance by boosting the level of trust. Public participation attenuates son preference when it stimulates higher trust that enhances the perceived quality of family planning services.

To the best of our knowledge, no previous study has considered the context-contingent effect. This study elaborates how context might shape the precise way in which public participation influences governance performance. Our results show that gender-imbalance risk at the individual level acts as a moderator in the relationship between public participation and governance performance. The moderating effect between civic autonomy and perceived quality is positive, which is opposite to what we expected. Previous research shows that risk perception is detrimental to public participation and evaluating the quality of public services (Huang and Zhu 2015; Poetz 2012). However, the present study suggests that the positive relationship between civic autonomy and perceived quality is stronger when the risk perception of gender imbalance is strong than when it is weak. Increased risk perception enhances the value of civic autonomy in public governance, or civic autonomy leverages more contribution from increased risk perception.

\subsection{Policy Implications}

While the governance of gender imbalance does not equate to family planning services, the perceived quality of family planning services and son preference reflect to some extent the performance of gender imbalance governance at the micro level. Family planning services are of political salience because the perceived quality has a noticeably large effective impact on son preference. Our findings highlight useful policy implications.

Public participation can improve governance performance in authoritarian countries. Policymakers and practitioners should exploit more participative governance and encourage the public to get involved in decision making, management, and monitoring. This involves decentralization of governance processes. In addition, governance should stress improvement of organization involvement to become proactive and selective. By transcending administrative boundaries and fostering civic spirit, costs can be lowered, and governance performance can be enhanced.

The role of trust should be of central importance in developing policy aimed at facilitating better governance performance in the public sector. This suggests an upward spiral of "the more public participation - the greater trust-and better governance performance". The moderating role of risk perception suggests that public authorities are obliged to alleviate the burden of high risks from residents. It is essential to use mass media to publicize the severe consequences and risks of gender imbalance in China.

\section{Limitations and Future Research}

There are some potential limitations to our study. First, there is the cross-sectional data design, making our study mainly a static analysis of the hypothesized relations. Moreover, we must note that our model and findings apply to only one context, the Chinese, and its generalizability is open to question. Second, although we avoided the problem of common method bias using the structural equation model, addition of more objective measures of governance performance alongside the subjective measures may improve the reliability of the findings. Finally, there are other potential mediators and moderators in the relationship between public participation and governance performance, and we did not compare our model to other alternative models to seek a comprehensive explanation. In addition, we cannot eliminate reverse causality, which may originate through different mechanisms. For instance, a previous study about trust, participation, and performance in public administration found that trust is positively affected by governance performance (Mizrahi et al. 2009).

Nonetheless, these limitations should not minimize the value of this research. The impact of public participation on governance performance and how trust influences that impact in the specific context of China is a very interesting topic. We suggest that future studies might use a more representative sample to continue this research. Perhaps 
our model can act as a starting point to investigate whether our findings apply in other sociopolitical environments and for governance of other public affairs.

Author Contributions: Conceptualization, R.S., S.L. and M.W.F.; methodology, R.S., S.L. and M.W.F.; software, R.S.; validation, R.S., S.L. and M.W.F.; formal analysis, R.S., S.L. and M.W.F.; investigation, R.S. and S.L.; resources, S.L.; data curation, S.L.; writing-original draft preparation, R.S.; writing-review and editing, S.L. and M.W.F.; visualization, R.S. and S.L.; supervision, M.W.F.; project administration, S.L.; funding acquisition, S.L. All authors have read and agreed to the published version of the manuscript.

Funding: This research was funded by the National Social Science Fund of China, grant number 16CRK022.

Institutional Review Board Statement: This study was determined to not meet the definition of "research with human subjects".

Informed Consent Statement: Informed consent was obtained from all subjects involved in the study.

Data Availability Statement: The data presented in this study are available on request from the corresponding author. The data are not publicly available because of privacy considerations.

Conflicts of Interest: The authors declare no conflict of interest.

\section{Appendix A}

Measurement model:

$$
\begin{aligned}
& \chi=\Lambda_{\chi} \xi+\delta \\
& y=\Lambda_{y} \eta+\varepsilon
\end{aligned}
$$

Structural model:

$$
\eta=\mathrm{B \eta}+\Gamma \xi+\zeta
$$

Here $\chi$ and $y$ are vectors of indicators, exogenous and endogenous, respectively. $\Lambda_{\chi}$ and $\Lambda_{y}$ are matrices of factor loadings. $\xi$ is a vector of exogenous latent variables (risk perception), $\eta$ is a vector of endogenous latent variables (civic autonomy, organizational involvement, government trust, social trust, perceived quality, and son preference). Error terms for indicators are $\delta$ for $\chi$ and $\varepsilon$ for $\mathrm{y} . \zeta$ is a vector of errors or disturbances for endogenous latent variables. $B$ is a parameter matrix for the relations among the endogenous latent variables, and $\Gamma$ is a parameter matrix for the regressions of the exogenous latent variables on the endogenous latent variables.

\section{Appendix B}

Table A1. Constructs, survey items, and standardized factor loadings.

\begin{tabular}{clc}
\hline Constructs & \multicolumn{1}{c}{ Survey Items } & Factor Loadings \\
\hline & In the past 3 years, have you participated in public affairs activities of the village & \\
organized by the Party? & $0.878^{\text {a }}$ \\
Civic Autonomy(CA) & In the past 3 years, have you participated in the management of public affairs, such \\
$\alpha=0.869$ & as giving advice to your community/village? & 0.978 \\
& In the past 3 years, have you reported the situation or made policy \\
& recommendations to relevant government departments in various ways? & 0.817 \\
& Fitness/sports activities & $0.676^{\text {a }}$ \\
& Entertainment activities & 0.726 \\
Organizational Involvement(OI) & Social activities & 0.550 \\
$\alpha=0.823$ & Religious activities & 0.365 \\
& Activities that help to develop/educate children's abilities & 0.657 \\
& Activities that help improve individual skills/techniques & 0.699 \\
& Charitable / compulsory activities & 0.755 \\
\hline
\end{tabular}


Table A1. Cont.

\begin{tabular}{|c|c|c|}
\hline Constructs & Survey Items & Factor Loadings \\
\hline \multirow{5}{*}{$\begin{array}{l}\text { Government Trust(GT) } \\
\qquad \alpha=0.791\end{array}$} & Trust in the village/community & $0.691^{\mathrm{a}}$ \\
\hline & Trust in governance resources owned by the village/community & 0.624 \\
\hline & Trust in public services offered by the village/community & 0.688 \\
\hline & Trust in information released by the village/community & 0.558 \\
\hline & Trust in the village/community staff & 0.706 \\
\hline \multirow{6}{*}{$\begin{array}{l}\text { Social Trust(ST) } \\
\qquad \alpha=0.838\end{array}$} & Residents in the village/community can communicate with you & $0.688^{\mathrm{a}}$ \\
\hline & Residents in the village/community think you are trustworthy & 0.704 \\
\hline & Residents in the village/community would consider your interests & 0.590 \\
\hline & You can discuss with residents of the village/community when you have a problem & 0.726 \\
\hline & You think residents of the village/community are trustworthy & 0.725 \\
\hline & You consider the interests of residents of the village/community & 0.666 \\
\hline \multirow{9}{*}{$\begin{array}{l}\text { Risk Perception(RP) } \\
\quad \alpha=0.815\end{array}$} & High marriage expenses & $0.341^{\mathrm{a}}$ \\
\hline & Many unmarried males over 30 years old & 0.506 \\
\hline & Trafficking in women and children & 0.576 \\
\hline & Safety issues for left-behind women and children & 0.570 \\
\hline & Extramarital relationships & 0.677 \\
\hline & Irregular marriages, such as mercenary marriage and early marriage & 0.633 \\
\hline & Increasing crime rate due to more unmarried men & 0.668 \\
\hline & Forced bachelor families face enormous economic pressure & 0.543 \\
\hline & Forced bachelor families face problems of old-age support & 0.567 \\
\hline \multirow{4}{*}{$\begin{array}{l}\text { Perceived Quality(PQ) } \\
\qquad \alpha=0.752\end{array}$} & To what extent has the family planning services met your needs? & $0.613^{\mathrm{a}}$ \\
\hline & $\begin{array}{l}\text { If a friend were in need of similar help, would you recommend the family planning } \\
\text { department to him or her? }\end{array}$ & 0.717 \\
\hline & $\begin{array}{l}\text { Have the family planning services you received helped you to deal more effectively } \\
\text { with your problems? }\end{array}$ & 0.816 \\
\hline & $\begin{array}{l}\text { If you were seek to help again, would you come back to the family planning } \\
\text { department? }\end{array}$ & 0.837 \\
\hline \multirow{5}{*}{$\begin{array}{l}\text { Son Preference(SP) } \\
\qquad \alpha=0.889\end{array}$} & Old-age support & $0.716^{\mathrm{a}}$ \\
\hline & Financial support & 0.757 \\
\hline & Day-to-day care & 0.783 \\
\hline & Carrying on the family lineage and prestige & 0.818 \\
\hline & Emotional support & 0.832 \\
\hline
\end{tabular}

Note: ${ }^{\text {a }}$ For model identification purposes, loading is fixed at 1 for the indicator in the unstandardized solution.

\section{References}

Aiken, Leona S., and Stephen G. West. 1991. Multiple regression: Testing and Interpreting Interactions. London: Sage.

Albrecht, Frederike. 2017. Government accountability and natural disasters: The impact of natural hazard events on political trust and satisfaction with governments in Europe. Risk Hazards \& Crisis in Public Policy 8: 381-410. [CrossRef]

Andrews, Rhys. 2007. Civic culture and public service failure: An empirical exploration. Urban Studies 44: 845-63. [CrossRef]

Andrews, Rhys, and Gene A. Brewer. 2013. Social capital, management capacity and public service performance. Public Management Review 15: 19-42. [CrossRef]

Andrews, Rhys, George Boyne, and Richard M. Walker. 2011. The impact of management on administrative and survey measures of organizational performance. Public Management Review 13: 227-55. [CrossRef]

Bao, Guoxian, Xuejun Wang, Gary L. Larsen, and Douglas F. Morgan. 2012. Beyond New Public Governance: A value-based global framework for performance management, governance, and leadership. Administration $\mathcal{E}$ Society 45: 443-67. [CrossRef]

Beeri, Itai, Anna Uster, and Eran Vigoda-Gadot. 2019. Does performance management relate to good governance? A study of its relationship with citizens' satisfaction with and trust in israeli local government. Public Performance E Management Review 42: 241-79. [CrossRef]

Binder, Andrew R., Dietram A. Scheufele, Dominique Brossard, and Albert C. Gunther. 2011. Interpersonal amplification of risk? Citizen discussions and their impact on perceptions of risks and benefits of a biological research facility. Risk Analysis 31: 324-34. [CrossRef] [PubMed]

Browne, Michael W., and Cudeck Robert. 1993. Alternative ways of assessing model fit. In Testing Structural Equation Models. Edited by Kenneth A. Bollen and J. Scott Long. Newbury Park: Sage, pp. 136-62.

Carlin, Ryan E., Gregory J. Love, and Elizabeth J. Zechmeister. 2013. Natural disaster and democratic legitimacy: The public opinion consequences of Chile's 2010 earthquake and tsunami. Political Research Quarterly 67: 3-15. [CrossRef]

Chen, Jie. 2000. Subjective motivations for mass political participation in urban China. Social Science Quarterly 81: 645-62.

Chen, Jie, Narisong Huhe, and Chunlong Lu. 2011. Causal mechanisms between social trust and community governance. Chinese Journal of Sociology 31: 421-34.

Chen, Yuyu, Hongbin Li, and Lingsheng Meng. 2013. Prenatal sex selection and missing girls in China: Evidence from the diffusion of diagnostic ultrasound. Journal of Human Resources 48: 36-70. [CrossRef] 
Cuthill, Michael, and John Fien. 2005. Capacity building: Facilitating citizen participation in local governance. Australian Journal of Public Administration 64: 63-80. [CrossRef]

Eklund, Lisa. 2018. The sex ratio question and the unfolding of a moral panic? Notions of power, choice and self in mate selection among women and men in higher education in China. In Scarce Women and Surplus Men in China and India. Edited by Sharada Srinivasan and Shuzhuo Li. Cham: Springer, pp. 105-25.

Emerson, Kirk, Tina Nabatchi, and Stephen Balogh. 2012. An integrative framework for collaborative governance. Journal of Public Administration Research and Theory 22: 1-29. [CrossRef]

Enserink, Bert, and Joop Koppenjan. 2007. Public participation in China: Sustainable urbanization and governance. Management of Environmental Quality: An International Journal 18: 459-74. [CrossRef]

Falleti, Tulia G., and Julia F. Lynch. 2009. Context and causal mechanisms in political analysis. Comparative Political Studies 42: $1143-66$. [CrossRef]

Ferrin, Donald L., Kurt T. Dirks, and Pri P. Shah. 2006. Direct and indirect effects of third-party relationships on interpersonal trust. Journal of Applied Psychology 91: 870-83. [CrossRef]

Fischer, Frank. 2015. Participatory governance: From theory to practice. In The Oxford Handbook of Governance. Edited by David Levi-Faur. Oxford: Oxford University Press, pp. 458-69.

Fukuyama, Francis. 1995. Social capital and the global economy. Foreign Affairs 74: 89-103. [CrossRef]

Fung, Archon. 2015. Putting the public back into governance: The challenges of citizen participation and its future. Public Administration Review 75: 513-22. [CrossRef]

Gao, Yong. 2014. Pattern identification of relationships between participation and trust in government. Sociological Studies 29: 98-119.

Garson, G. David. 2013. Path Analysis. Asheboro: Statistical Associates Publishing Asheboro.

Giddens, Anthony. 1991. Modernity and Self-Identity: Self and Society in the Late Modern Age. Stanford: Stanford University Press.

Golley, Jane, and Rod Tyers. 2014. Gender 'rebalancing' in China. Asian Population Studies 10: 125-43. [CrossRef]

Guo, Zhen, Monica Das Gupta, and Shuzhuo Li. 2016. 'Missing girls' in China and India: Trends and policy challenges. Asian Population Studies 12: 135-55. [CrossRef]

He, Alex Jingwei, and Liang Ma. 2020. Citizen participation, perceived public service performance, and trust in government: Evidence from health policy reforms in Hong Kong. Public Performance \& Management Review, 1-23. [CrossRef]

Heikkila, Tanya, and Kimberley Roussin Isett. 2007. Citizen involvement and performance management in special-purpose governments. Public Administration Review 67: 238-48. [CrossRef]

Heikkila, Tanya, and Andrea K. Gerlak. 2013. Building a conceptual approach to collective learning: Lessons for public policy scholars. Policy Studies Journal 41: 484-512. [CrossRef]

$\mathrm{Hu}, \mathrm{Li}-$ Tze, and Peter M. Bentler. 1995. Evaluating model fit. In Structural Equation Modeling: Concepts, Issues, and Application. Edited by Rick H. Hoyle. Thousand Oaks: Sage, pp. 76-99.

$\mathrm{Hu}$, Rong, Ivan Y. Sun, and Yuning Wu. 2015. Chinese trust in the police: The impact of political efficacy and participation. Social Science Quarterly 96: 1012-26. [CrossRef]

Huang, Jie, and Zhengwei Zhu. 2015. The significance, practice and trends of social stability risk evaluation mechanism from the perspective of state governance. Chinese Public Administration 15: 62-67.

Huhe, Narisong, Jie Chen, and Min Tang. 2015. Social trust and grassroots governance in rural China. Social Science Research 53: 351-63. [CrossRef] [PubMed]

Irvin, Renée A., and John Stansbury. 2004. Citizen participation in decision making: Is it worth the effort? Public Administration Review 64: 55-65. [CrossRef]

Jiang, Quanbao, Shuzhuo Li, and Marcus W. Feldman. 2011. Demographic consequences of gender discrimination in China: Simulation analysis of policy options. Population Research and Policy Review 30: 619-38. [CrossRef]

Kathlene, Lyn, and John A. Martin. 1991. Enhancing citizen participation: Panel designs, perspectives, and policy formation. Journal of Policy Analysis and Management 10: 46-63. [CrossRef]

Kim, Soonhee, and Jooho Lee. 2012. E-participation, transparency, and trust in local government. Public Administration Review 72: 819-28. [CrossRef]

King, Cheryl Simrell, Kathryn M. Feltey, and Susel Bridget O'Neill. 1998. The question of participation: Toward authentic public participation in public administration. Public Administration Review 58: 317-26. [CrossRef]

Kline, Rex B. 2016. Principles and Practice of Structural Equation Modeling, 4th ed. New York: Guilford Press.

Klinke, Andreas. 2021. Public understanding of risk and risk governance. Journal of Risk Research 24: 2-13. [CrossRef]

Kumar, Sneha, and Nistha Sinha. 2020. Preventing more "missing girls": A review of policies to tackle son preference. The World Bank Research Observer 35: 87-121. [CrossRef]

Kweit, Mary Grisez, and Robert W. Kweit. 2004. Citizen participation and citizen evaluation in disaster recovery. The American Review of Public Administration 34: 354-73. [CrossRef]

Lee, Yunsoo, and Hindy Lauer Schachter. 2019. Exploring the relationship between trust in government and citizen participation. International Journal of Public Administration 42: 405-16. [CrossRef]

Li, Shuzhuo, Zijuan Shang, and Marcus W. Feldman. 2013. Social management of gender imbalance in China: A holistic governance framework. Economic and Political Weekly 48: 79-86. 
Lim, Da-Hee, Jeong-Min Oh, and Gi-Heon Kwon. 2016. Mediating effects of public trust in government on national competitiveness: Evidence from Asian countries. International Review of Public Administration 21: 125-46. [CrossRef]

Liu, Jinfa. 2014. From social management to social governance: Social conflict mediation in China. Journal of Public Affairs 14: 93-104. [CrossRef]

Loh, Charis, and Elizabeth J. Remick. 2015. China's skewed sex ratio and the one-child policy. The China Quarterly 222: 295-319. [CrossRef]

Łopaciuk-Gonczaryk, Beata. 2019. Does participation in social networks foster trust and respect for other people-Evidence from Poland. Sustainability 11: 1733. [CrossRef]

Ma, Liang, and Tom Christensen. 2019. Government trust, social trust, and citizens' risk concerns: Evidence from crisis management in China. Public Performance \& Management Review 42: 383-404. [CrossRef]

Mah, Daphne Ngar-yin, Peter Hills, and Julia Tao. 2014. Risk perception, trust and public engagement in nuclear decision-making in Hong Kong. Energy Policy 73: 368-90. [CrossRef]

McCracken, Melody Je, Thomas F. McIlwain, and Myron D. Fottler. 2001. Measuring organizational performance in the hospital industry: An exploratory comparison of objective and subjective methods. Health Services Management Research 14: 211-19. [CrossRef] [PubMed]

Michels, Ank. 2011. Innovations in democratic governance: How does citizen participation contribute to a better democracy? International Review of Administrative Sciences 77: 275-93. [CrossRef]

Mizrahi, Shlomo, Eran Vigoda-Gadot, and Nissim Cohen. 2009. Trust, participation, and performance in public administration. Public Performance \& Management Review 33: 7-33. [CrossRef]

Mizrahi, Shlomo, Eran Vigoda-Gadot, and Nissim Cohen. 2010. Trust, participation and performance. Public Management Review 12: 99-126. [CrossRef]

Morgeson, Forrest V., III, David VanAmburg, and Sunil Mithas. 2011. Misplaced trust? Exploring the structure of the e-governmentcitizen trust relationship. Journal of Public Administration Research and Theory 21: 257-83. [CrossRef]

Murphy, Rachel. 2014. Sex ratio imbalances and China's care for girls programme: A case study of a social problem. The China Quarterly 219: 781-807. [CrossRef]

Neshkova, Milena I., and Hai Guo. 2012. Public participation and organizational performance: Evidence from state agencies. Journal of Public Administration Research and Theory 22: 267-88. [CrossRef]

Newig, Jens, Edward Challies, Nicolas W. Jager, Elisa Kochskaemper, and Ana Adzersen. 2018. The environmental performance of participatory and collaborative governance: A framework of causal mechanisms. Policy Studies Journal 46: 269-97. [CrossRef]

Nguyen, Tuan D., C. Clifford Attkisson, and Bruce L. Stegner. 1983. Assessment of patient satisfaction: Development and refinement of a Service Evaluation Questionnaire. Evaluation and Program Planning 6: 299-313. [CrossRef]

Nie, Jing-Bao. 2010. Limits of state intervention in sex-selective abortion: The case of China. Culture, Health E Sexuality 12: 205-19. [CrossRef]

Nooteboom, Bart. 2002. Trust: Forms, Foundations, Functions, Failures and Figures. Cheltenham and Northampton: Edward Elgar.

Nunnally, Jum C., and Ira H. Bernstein. 1994. Psychometric Theory, 3rd ed. New York: Tata McGraw-hill Education.

Nyhan, Ronald C. 2000. Changing the paradigm: Trust and its role in public sector organizations. The American Review of Public Administration 30: 87-109. [CrossRef]

Oh, Youngmin, and Carrie Blanchard Bush. 2014. Exploring the role of dynamic social capital in collaborative governance. Administration \& Society 48: 216-36. [CrossRef]

Osborne, Stephen P. 2006. The new public governance? Public Management Review 8: 377-87. [CrossRef]

Owen, Catherine. 2020. Participatory authoritarianism: From bureaucratic transformation to civic participation in Russia and China. Review of International Studies 46: 415-34. [CrossRef]

Poetz, Anneliese. 2012. "Risk is a social thing, not just a mathematical thing:" A model for stakeholder engagement in decision making. Risk, Hazards \& Crisis in Public Policy 3: 1-32. [CrossRef]

Putnam, Robert D. 2000. Bowling Alone: The Collapse and rEvival of American Community. New York: Simon and Schuster.

Putnam, Robert D, Robert Leonardi, and Raffaella Y Nanetti. 1993. Making Democracy Work: Civic Traditions in Modern Italy. Princeton: Princeton University Press.

Sashkin, Marshall. 1984. Participative management is an ethical imperative. Organizational Dynamics 12: 5-22. [CrossRef]

Seller, Enrique Pastor. 2017. Mechanisms for participation in the public system of social services in Spain: Opportunities for the development of social work with a citizenist approach. European Journal of Social Work 20: 441-58. [CrossRef]

Shim, Junseop, and Ji-Hyung Park. 2016. Public participation and trust in government: The case of the Korean financial regulatory agency. Public Performance \& Management Review 40: 1-22. [CrossRef]

Siebers, Vinitha, Raymond Gradus, and René Grotens. 2019. Citizen engagement and trust: A study among citizen panel members in three Dutch municipalities. The Social Science Journal 56: 545-54. [CrossRef]

Six, Frédérique, Bart Nooteboom, and Adriaan Hoogendoorn. 2010. Actions that build interpersonal trust: A relational signalling perspective. Review of Social Economy 68: 285-315. [CrossRef]

Somma, Nicolás M. 2010. How do voluntary organizations foster protest? The role of organizational involvement on individual protest participation. The Sociological Quarterly 51: 384-407. [CrossRef] 
Speer, Johanna. 2012. Participatory governance reform: A good strategy for increasing government responsiveness and improving public services? World Development 40: 2379-98. [CrossRef]

Suebvises, Ploy. 2018. Social capital, citizen participation in public administration, and public sector performance in Thailand. World Development 109: 236-48. [CrossRef]

UNFPA, and CPDRC. 2018. Addressing Gender-Biased Sex Selection and Skewed Sex Ratio at Birth in China: Case Summary. New York: UNFPA.

Uslaner, Eric M., and Richard S. Conley. 2003. Civic engagement and particularized trust: The ties that bind people to their ethnic communities. American Politics Research 31: 331-60. [CrossRef]

Wachinger, Gisela, Ortwin Renn, Chloe Begg, and Christian Kuhlicke. 2013. The risk perception paradox-Implications for governance and communication of natural hazards. Risk Analysis 33: 1049-65. [CrossRef] [PubMed]

Wang, XiaoHu, and Montgomery Wan Wart. 2007. When public participation in administration leads to trust: An empirical assessment of managers' perceptions. Public Administration Review 67: 265-78. [CrossRef]

Welter, Friederike, and David Smallbone. 2011. Institutional perspectives on entrepreneurial behavior in challenging environments. Journal of Small Business Management 49: 107-25. [CrossRef]

Williamson, Oliver E. 1999. Strategy research: Governance and competence perspectives. Strategic Management Journal 20: 1087-108. [CrossRef]

Xia, Min. 2011. Social capital and rural grassroots governance in China. Journal of Current Chinese Affairs 40: 135-63. [CrossRef]

Xie, Zhiju. 2013. Peasants' risk perception and behavior choice for rural social risks in China' s Western regions. Journal of Nanjing Agricultural University (Social Sciences Edition) 13: 12-21.

Xie, Yuhua, and Qunyan Zhang. 2013. Influence of employee participation on new generation employees' satisfaction. Chinese Journal of Management 10: 1162-69.

Xu, Zhihua, Jingzhu Shan, Jingmei Li, and Wensi Zhang. 2020. Extending the theory of planned behavior to predict public participation behavior in air pollution control: Beijing, China. Journal of Environmental Planning and Management 63: 669-88. [CrossRef]

Xue, Lan, and Kaibin Zhong. 2012. Domestic reform and global integration: Public administration reform in China over the last 30 years. International Review of Administrative Sciences 78: 284-304. [CrossRef]

Yang, Kaifeng, and Sanjay K. Pandey. 2011. Further dissecting the black box of citizen participation: When does citizen involvement lead to good outcomes? Public Administration Review 71: 880-92. [CrossRef]

Yang, Bao, Yufei He, and Wenjin Long. 2016. Alienation of civic engagement in China? Case studies on social governance in Hangzhou. VOLUNTAS: International Journal of Voluntary and Nonprofit Organizations 27: 2150-72. [CrossRef]

Zhang, Huan, and Jing Hu. 2014. A study on social governance evaluation indexes: A public-oriented perspective. Journal of Sichuan University (Social science Edition) 14: 120-26.

Zukin, Cliff, Scott Keeter, Molly Andolina, Krista Jenkins, and Michael X. Delli Carpini. 2006. A New Engagement?: Political Participation, Civic Life, and the Changing American Citizen. Oxford: Oxford University Press. 